\author{
Asian Journal of \\ Medical and Biological Research \\ ISSN 2411-4472 (Print) 2412-5571 (Online) \\ www.ebupress.com/journal/ajmbr
}

\title{
Article \\ Identification of genera of tubificid worms in Bangladesh through morphological study
}

\author{
Mariom*, Sharmin Nahar Liza and Md. Fazlul Awal Mollah
}

Department of Fisheries Biology and Genetics, Faculty of Fisheries, Bangladesh Agricultural University, Mymensingh-2202, Bangladesh

*Corresponding author: Mariom, Department of Fisheries Biology and Genetics, Faculty of Fisheries, Bangladesh Agricultural University, Mymensingh-2202, Bangladesh. E-mail: mariom.bau@ gmail.com

Received: 12 January 2016/Accepted: 17 January 2016/ Published: 31 March 2016

\begin{abstract}
Tubificids are aquatic oligochaete worms (F- Naididae, O- Haplotaxida, P- Annelida) distributed all over the world. The worms are very important as they are used as live food for fish and other aquatic invertebrates. A step was taken to identify the genera of tubicifid worms that exist in Mymensingh district, Bangladesh on the basis of some external features including the shape of their anterior (prostomium) and posterior end, number of body segment and arrangement of setae. The study result indicated the existence of three genera among the tubificid worms. These were Tubifex, Limnodrilus and Aulodrilus. All these three genera possessed a cylindrical body with a bilateral symmetry formed by a series of metameres. The number of body segments ranged from 34 to 120 in Tubifex, 50 to 87 in Limnodrilus, and 35 to 100 in Aulodrilus. In Tubifex, the first segment, with the prostomium, was round or triangular bearing appendages, whereas, in Limnodrilus and Aulodrilus, the prostomium without appendages was triangular and conical, respectively. Three types of setae i.e., hair setae, pectinate setae and bifid setae of various sizes were found in Tubifex, whereas, Limnodrilus possessed pectinate setae and bifid setae of more or less similar size and shape; and Aulodrilus possessed only hair setae and bifid setae of different size.
\end{abstract}

Keywords: genera; identification; morphology; tubificid worms

\section{Introduction}

Tubificid worms are the small Annelids abundant in drains and other marshy areas rich in organic matters. They are widely used for feeding of many fish larvae to produce stockable sized seeds in the hatcheries. They are also used in keeping aquarium/ornamental fishes. To the aquarium fish keepers the demand of these worms is considerably high. They get the supply from different aquarium shops of Dhaka. Although the data are not available the amount of tubificid worms supplied to these aquarium shops and ultimately sold to the ornamental fish culturists is substantial. Some hatcheries also use these worms to certain extent for larvae nursing purposes. Steps were taken to study the basic biology and life history (Brinkhurst and Kenedy, 1965) in order to develop suitable culture techniques of tubificid worms (Marian and Pandian, 1984; Mariom and Mollah, 2012). The tubificid worms seem to inhabit the soft sediments rather than relatively unpopulated bare streams (Ladle, 1971) and laboratory production also reflect the similar results. In Targe Lake of South Sweeden, oligochaete species (eg. L. hoffmeisteri and T. tubifex) were found in great abundance $\left(120 \mathrm{~m}^{-2}\right)$ in situation of extreme organic enrichment (Milbrink, 1983). In northern Iraq, L. profundicola was only recorded by Ali (2007) in Grater Zab River. In Bangladesh, the worms are collected from habitats that are rich in organic matter, such as drains, canals etc. Collection from these places is not only troublesome and hazardous but also unhealthy and sometimes causes outbreaks of disease in the larvae fed with these worms. After heavy shower most of them are washed away and the availability decreases to the minimum. Moreover, this practice of collecting the worms from the wild sources might also cause an imbalance in the biodiversity soon if it has not happened already. 
Though, some works specially on taxonomy and biology of tubificid worms have been done by some researchers, but relatively less work has been done on the identification of genera of tubificid worms. So, it remains as an important aspect to conduct research to see how many genera make the group tubificid. From the literature search it is presumed that genera like Tubifex, Limnodrilus, Branchiura, Aulodrilus etc. might be the major representatives of the family Naididae in Bangladesh. If so, identification of each of the genus is of special importance. A particular genus may exhibit higher or lower growth rate needing some changes in media composition and management matters. And thus, culture of one genus may prove to be more profitable than the others. Since aquaculture is an industry, the question of profit and loss obviously arises well ahead of any other considerations. The research work was therefore conducted to find out the existing genera of tubificid worms.

\section{Materials and Methods}

\subsection{Research site and duration}

The experiment was conducted in the laboratory of the department of Fisheries Biology and Genetics under the Faculty of Fisheries, Bangladesh Agricultural University (BAU), Mymensingh during the period of January 2014 to June 2015.

\subsection{Working procedure}

To identify the existing genera of tubificid worms, samples were collected from different drains of Mymensingh region and taken to the Mini Hatchery and Breeding Complex of the Faculty of Fisheries. Then the samples were cleaned using running water. The cleaned specimens were transferred to a petridish with clear water and kept for some time. The live specimens were taken on slide and smoothly covered with cover slip so that the worms were not crushed. Then the worms were observed under high power microscope (OLYMPUS-CX21, Japan) and several snaps of different positions were taken using the camera of the microscope. This procedure was repeated several times to get the desired criteria used for identification. On the basis of the morphological characters found from these photographs their genera were identified according to Bonomi and Erseus (1984).

\section{Results and Discussion}

Tubificid worms are the most common aquatic oligochaeta in freshwater habitats. The study indicated the existence of three genera i.e., Tubifex, Limnodrilus and Aulodrilus among the tubificid worms. These three genera of tubificid worms were identified depending on their external features including the shape of their anterior (prostomium) and posterior end, number of body segment and arrangement of setae. A brief description of each of these three genera is given below.

\subsection{Tubifex}

Tubifex spp. like all oligochaetes, had a segmented body. The number of body segments ranged between 34 and 120 (Holmquist, 1983). The first segment, with the prostomium, carried the mouth. This first segment had appendages. The prostomium was round or triangular (Figure 1a). The terminal pointed segment contained the anus (Figure 1b). The periostomium was free of setae in Tubifex which appeared on segment II (Figure 1c). Each body segment had four bundles of setae, two in dorso-lateral and two in ventro-lateral position (Figures 1d and 1e). The dorsal and ventral setae of each segment were different in terms of their shape (Bouche et al., 1999). There were two types of dorsal setae: pectinate setae and hair setae. The hooks at the end of the pectinate setae formed combs, with the two exterior larger than the interior teeth. The hair setae were adorned with fine elements, named serrations (Figure 1d). All ventral setae were of one type and all had bifid tips (Figure 1e). The number of setae in the dorsal and ventral bundles varied between individuals, but the number of setae always decreased from the front to the rear of the body (Chapman and Brinkhurst, 1986). The bundles on the anterior segments contained 2-4 pectinate setae, 1-3 hair setae and 2-4 bifid setae, while the dorsal and ventral bundles on the posterior part of the body had only a single seta. Hair setae disappeared and pectinate setae became bifid toward the posterior end. All posterior setae were of the bifid type. The size of the setae (bifid, pectinate and hair) changed along the body, as a function of its diameter. They became much larger between segments II and $\mathrm{V}$, then remained at the same size up to the clitellum (segments X, XI and XII), thereafter gradually becoming smaller (Bouche et al., 1999). The size of hair setae was 2-4 times larger than those of the pectinate setae.

The shape, number and distribution of the chaetae constitute taxonomic criteria in oligochaetes (Bouche et al., 1999 and Holmquist, 1983). Tubifex spp. was a slender worm that may grow up to $20 \mathrm{~cm}$ in length. Among three genera of tubificid worms, Tubifex is larger than other two genera. Three types of setae were found in Tubifex spp.: hair setae, pectinate setae and bifid setae. The size of setae varied which is also shown by Bouche 
et al. (1999). Chaetae are important in the taxonomy of aquatic oligochaetes; which are the only identification criterion for oligochaetes those are not sexually mature (Steinlechner, 1987).

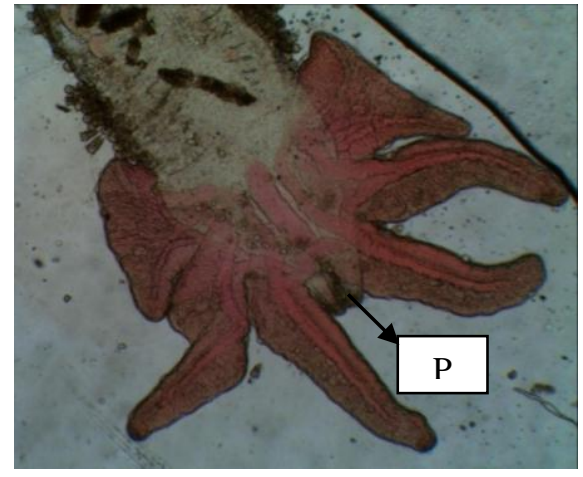

a

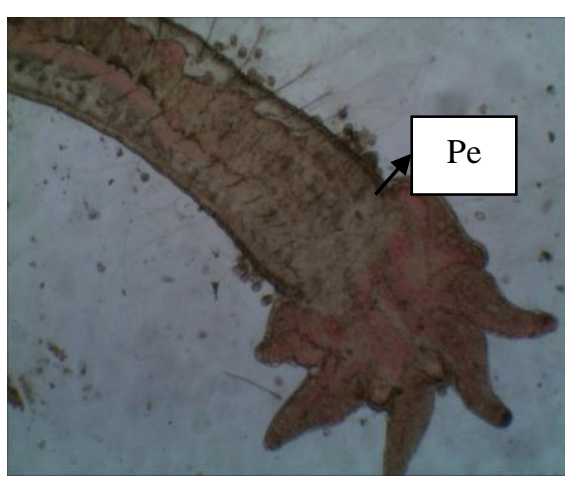

c

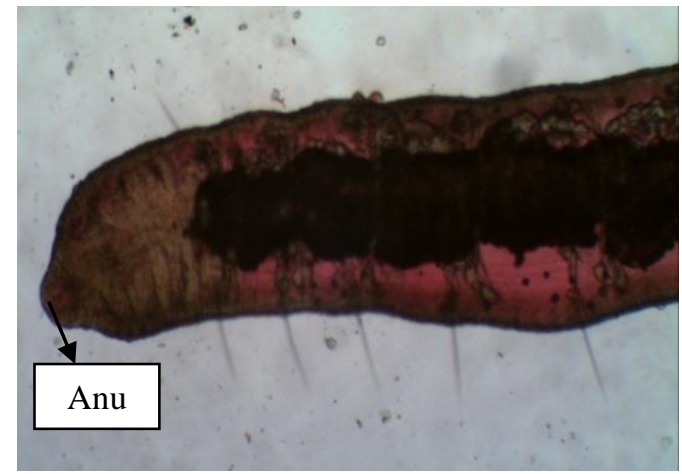

b

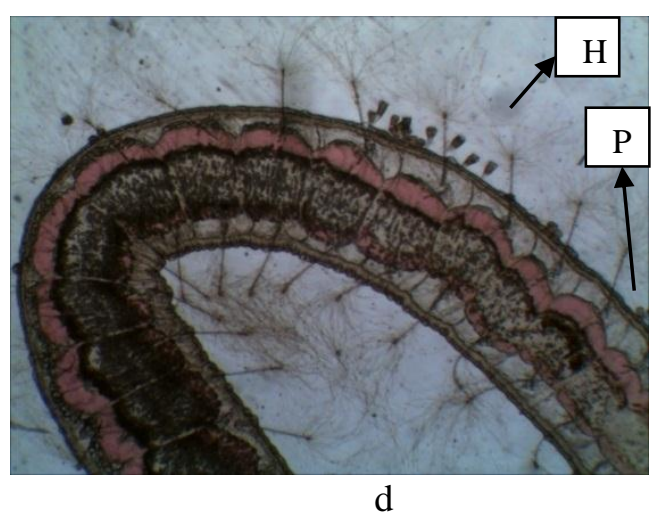

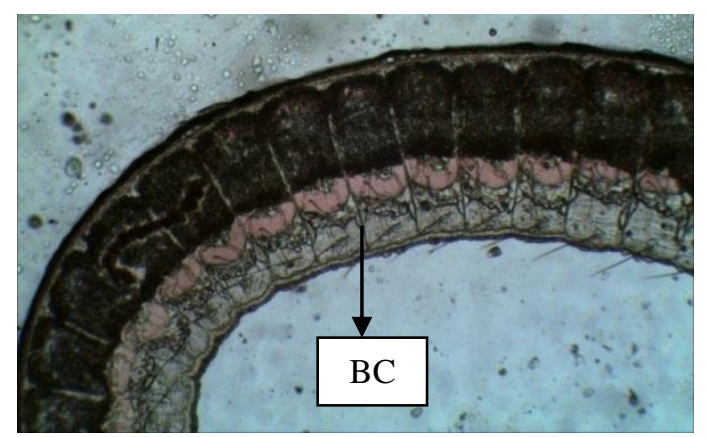

e

Figure 1. The morphology of Tubifex a) First segment showing triangular prostomium (P); b) Terminal segment bearing anus; c) Second segment showing periostomium (Pe); d) Setae in dorso-lateral position (HC- hair setae, PC- pectinate setae), e) Setae in ventro-lateral position (BC- bifid setae). 


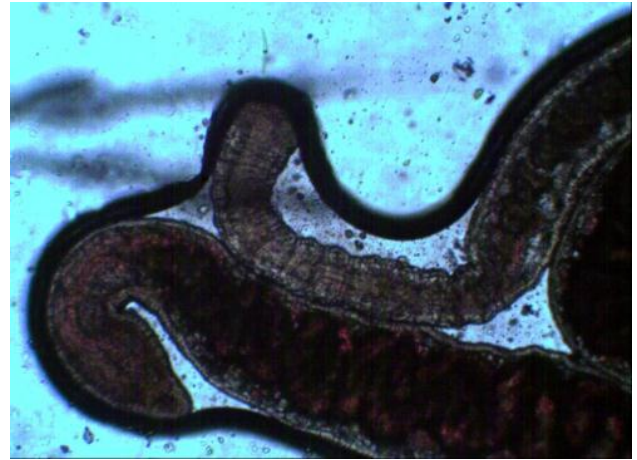

a

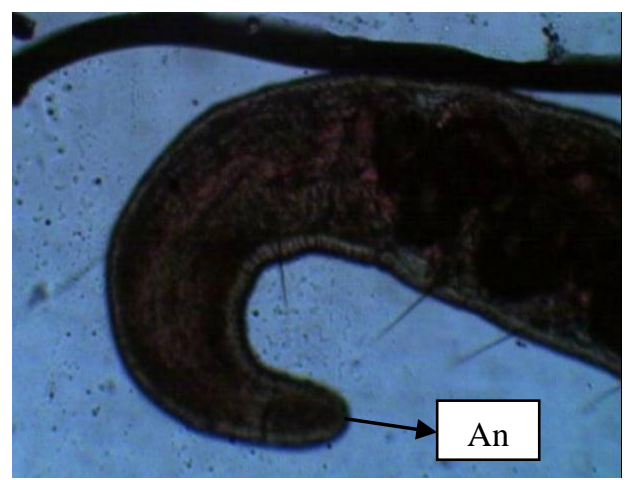

$\mathrm{C}$

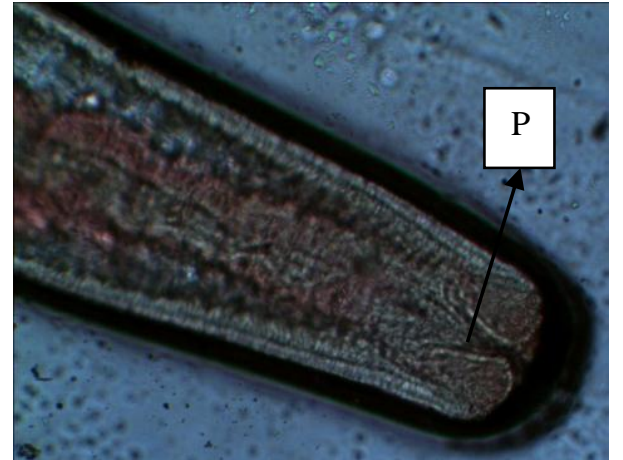

$\mathrm{b}$

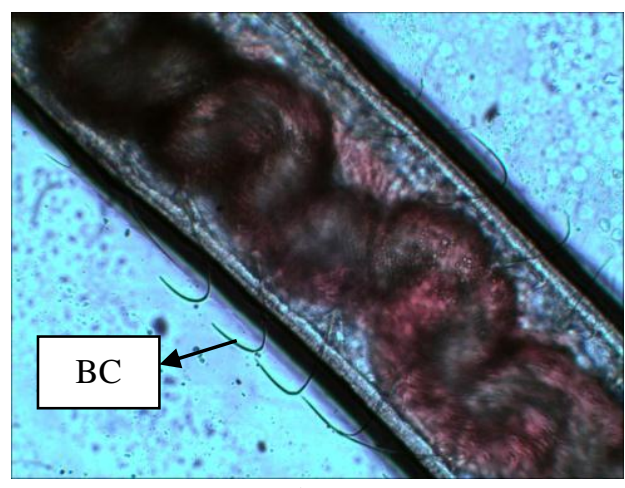

$\mathrm{d}$

Figure 2. The morphology of Limnodrilus a) The segmented and slender worm; b) Anterior end showing prostomium; c) Posterior end bearing anus; d) Arrangement of setae (BC-bifid setae).

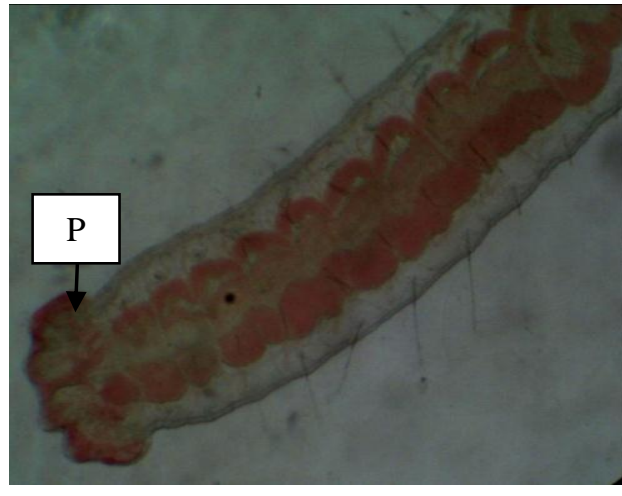

a

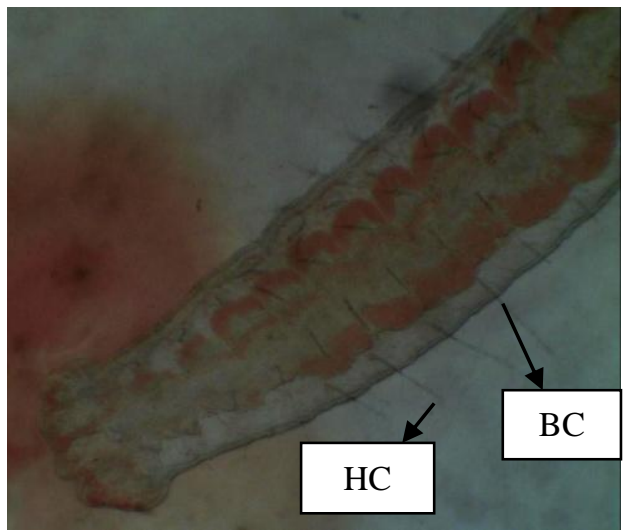

c

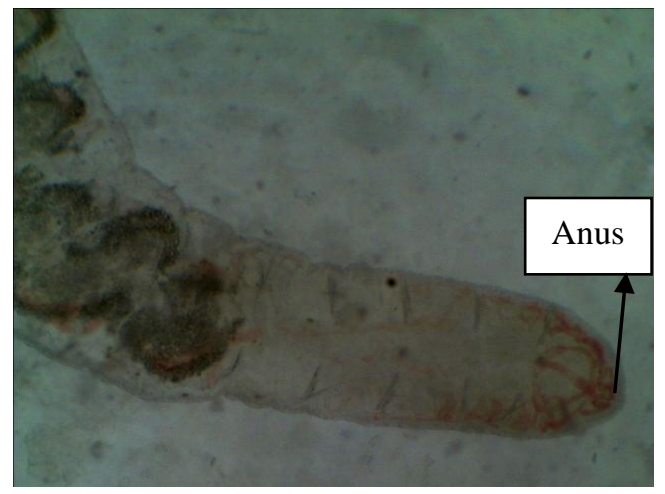

b

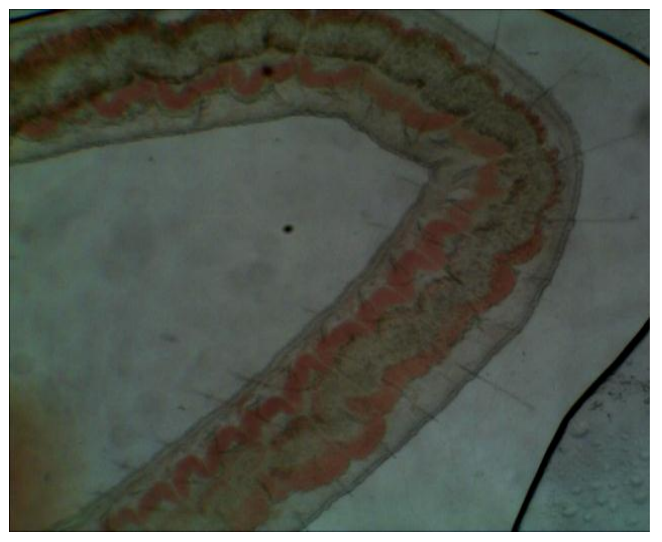

d

Figure 3. The morphology of Aulodrilus a) Anterior end showing prostomium; b) Posterior end bearing anus; c) Anterior dorsal bundles with hair setae (HC) and bifid setae (BC); d) Anterior ventral setae. 


\subsection{Limnodrilus}

Limnodrilus spp. had segmented slender (Figure 2a) body ranged from 50 to 80 segments. Brinkhurst and Jameison (1971) reported that the number of body segment ranged between 50 and 90 . The body wall of Limnodrilus was smooth with an average length of about $42 \mathrm{~mm}$, with 87 segments (Jaweir, 2011). The first segment which carried the mouth was also called prostomium but had no appendages like tubificid worms (Figure 2b). The shape of prostomium was triangular. The last segment carried a pointed anus (Figure 2c). Limnodrilus spp. in general were tubificid worms without hair setae and with most anterior setae bifid (Figure 2d). Posterior parts of the worms contained pectinate setae. The dorsal and ventral setae were quite similar in shape, but decreased numerically toward the posterior end. All setae, dorsal and ventral, were of about equal length. Usually, 5-7 setae in dorsal bundles, and 4-6 in ventral bundle were observed. The region dissimilarity of setae was noticed only in L. udekemianus by Jaweir (2011), where the anterior bundles had setae with upper tooth thicker and at least twice as long as the lower, bent almost at a right angle and the posterior setae with equal teeth. Clitellum was found in segment XI. Two types of setae were found: pectinate and bifid setae. All setae were quite similar in shape. Timm (2009) also reported that, all setae whether dorsal or ventral, are of about equal length.

\subsection{Aulodrilus}

Aulodrilus spp. had smooth body surface with segment number ranging from 35 to 100 . According to Jaweir (2011), the worms had an average length of about $9 \mathrm{~mm}$, with the body comprising 88 segments. The body length of Aulodrilus ranged between 2 and $28 \mathrm{~mm}$. Timm (2009) recorded length to range only between 5 and $12 \mathrm{~mm}$; While Brinkhurst (1971) recorded it to be between 2 and $23 \mathrm{~mm}$. The prostomium was short and conical in shape (Figure 3a). Like Limnodrilus, the prostomium of Aulodrilus had no appendages. Rounded last segment was anus (Figure 3b). The dorsal bundles were with hair and bifid setae, but no pectinate setae, present (Figure 3c). The anterior dorsal bundles of segments II-III were composed of 4 setae, in addition to one small simple pointed seta. Segments IV-VII appeared with 1-2 hair setae and 4-5 bifid crotchets (Figure 3c), all setae from IIVII, with upper tooth being shorter and thinner than the lower one. Beyond segment VII, usually from IX, the bifid setae were oar-shaped; their tips rounded and sometimes were slightly bifid. These setae, 2-3 per bundle, occurred in all bundles up to the end of the body. The anterior ventral setae, with 4-6 crotches (less in the posterior region), had their upper tooth shorter than the lower one (Figure 3d), diverting under a cute angle, and had distal modulus.

In Aulodrilus, two types of setae were found: hair setae and bifid setae. The size of setae varied. This species is characterized by the presence of oar-shaped setae in the dorsal bundle, beyond segment VII, and the absence of hair setae in the first few bundles (Brinkhurst and Jameison, 1971).

All the three genera of tubificid worms (Tubifex, Limnodrilus and Aulodrilus) possessed a cylindrical body with a bilateral symmetry formed by a series of metameres. The identification of genera of tubificid worms was important for uniform production of tubificid worms. Some works regarding the identification of tubificid worms were done by some researchers abroad. In Lake Constance, 14 species of tubificid were reported by Steinlechner (1987). Similar study was done by Brinkhurst (1971) where he recorded 32 species of oligochaetes under the family of Tubificidae. Present study indicated that, Tubifex, Limnodrilus and Aulodrilus etc. might be the major representatives of the family Naididae in Bangladesh.

\section{Conclusions}

Pure culture with a particular genus may prove to be more profitable than the others. In this context, identification of three genera i.e. Tubifex, Limnodrilus and Alodrilus can be stated as a landmark toward development of sustainable culture technique for tubificid worms.

\section{Conflict of interest}

None to declare.

\section{References}

Ali LAQ, 2007. A study of macroinvertebrates community in the middle sector of Greater Zab River, Iraq. $\mathrm{Ph} . \mathrm{D}$. Thesis, College of Science for Women, University of Baghdad, Iraq.

Bonomi G and C Erseus, 1984. Aquatic oligocheata. Proceedings of the second International Symposium on aquatic oligocheate biology, held in Pallanza, Italy, September 21-24, pp. 240.

Bouche ML, BR Sylvie and G Vernet, 1999. A light and scanning electron microscope study of the morphology of the chaetae of Tubifex tubifex in a non-polluted medium. Hydrobiologia, 411: 39-44. 
Brinkhurst RO, 1971. A guide for the identification of British aquatic oligochaeta. Freshwater Biological Association, Scientific Publication No. 22 (second ed.), 55 p.

Brinkhurst RO and BG Jamieson, 1971. The aquatic oligochaeta of the world. Edinburgh, Oliver and Boyd. XI, $860 \mathrm{p}$.

Brinkhurst RO and CR Kennedy, 1965. Studies on the biology of tubificidae (Annelida, Oligochaeta) in a polluted stream. Journal of Animal Ecology, 34: 429-443.

Chapman PM and RO Brinkhurst, 1986. Setal morphology of the oligochaetes Tubifex tubifex and Ilyodrilus frantzi (capillatus) as revealed by SEM. Proceedings of the Biological Society of Washington, 99: 323-327.

Holmquist C, 1983. What is Tubifex tubifex (OF Müller) (Oligochaeta: Tubificidae)? Zoologica Scripta, 12: 187-201.

Jaweir HJ, 2011. A new record of three tubificid species (Annelida: Oligochaeta) from Al-Hawiezah marsh, Iraq. Mesopotamium Journal of Marine Science, 26: 114-121.

Ladle M, 1971. The biology of the oligochaetes as live food in commercial aquaculture. Hydrobiologia, 155: 309-310.

Marian MP and TJ Pandian, 1984. Culture and harvesting techniques of Tubifex tubifex. Aquaculture, 42: 303315.

Mariom and MFA Mollah, 2012. Development of a suitable culture medium for the production of tubificid worms. Asian Fisheries Science, 25: 40-51.

Milbrink G, 1983. An improved environmental index based on the relative abundance of oligochate species. Hydrobiologia, 102: 89-97.

Steinlechner R, 1987. Identification of immature tubificid worms (Oligochaete) of Lake Constance and its influence on the evaluation of species distribution. Hydrobiologia, 155: 57-63.

Timm T, 2009. A guide to freshwater oligochaeta and polychaeta of northern and central Europe. Lauterbornia, 66: $1-23$. 